\title{
A prática da pesquisa no ensino superior: conhecimento pertencente na formação humana
}

\author{
Marisa Soares
}

Antonio Joaquim Severino

Resumo: Com base em nossa pesquisa de natureza qualitativa e por meio do estudo de caso evidenciamos a necessidade de compreender e analisar sobre as possibilidades didático pedagógicas da prática da pesquisa realizada nas atividades de Iniciação Científica, que em nossa experiência na universidade pesquisada tem se demonstrado, além de uma ponte de conexão entre os alunos da graduação com os projetos docentes da Pós-Graduação, uma perspectiva de uma formação profissional com qualidade. Para tanto, analisamos um universo amostral formado por professores, alunos e egressos de cursos de Pedagogia e Licenciaturas de uma universidade paulista, utilizamos o procedimento técnico de questionário ao se focalizar uma questão aberta, posto que objetivamos analisar o resultado pedagógico da prática da Iniciação Científica, com vistas a verificar até que ponto esta prática contribui para a aprendizagem significativa. Por aprendizagem significativa, entendemos a apropriação, pelo aprendiz, do próprio processo de construção do conhecimento e não somente de seus produtos, bem como a compreensão de sua inserção na produção da existência pessoal e social. Foram compulsadas fontes bibliográficas que tratam do processo de construção de conhecimento em relação com o processo de ensino e aprendizagem no ensino superior, explicitando nossas categorias teóricas de análise.

Palavras-chave: Ensino superior. Iniciação científica. Aprendizagem significativa.

\section{The practice of research in higher education: owned knowledge in human formation}

Abstract: Based on our research of a qualitative nature and through the case study, we highlight the need to understand and analyze pedagogical didactic possibilities of the practice of research carried out in the activities of scientific initiation, which in our experience in the researched university has been demonstrated, in addition A bridging bridge between undergraduate students and postgraduate teaching projects, a perspective of quality professional training. Therefore, we analyze a sample universe formed by teachers, students and graduates of Pedagogy and Graduation courses of a university in São Paulo, we used the technical procedure of questionnaire when focusing on an open question, since we aim to analyze the pedagogical result of the practice of Scientific Initiation, to verify to what extent this practice contributes to meaningful learning. By meaningful learning we mean the appropriation by the learner of the process of knowledge construction itself and not only of its products, as well as the understanding of its insertion in the production of personal and social existence. We used bibliographical sources that deal with the process of knowledge construction in relation to the teaching and learning process in higher education, explaining our theoretical categories of analysis.

Key words: Higher education. Scientific research. Meaningful learning. 


\section{Introdução}

Nesta pesquisa, dentro do âmbito da articulação entre o ensino e a pesquisa, focalizamos, para uma análise detida e mais aprofundada, uma modalidade específica de pesquisa: a Iniciação Científica, que perpassa toda a graduação, delimitando-se aqui os cursos de Pedagogia e de Licenciaturas. Assim, analisando a experiência da Universidade pesquisada, procuramos debater a seguinte questão: quais contribuições a prática de Iniciação Científica pode oferecer ao processo de ensino e aprendizagem entre alunos e professores orientadores dos cursos de Pedagogia e Licenciaturas?

Efetiva-se a importância de que o conhecimento seja construído mediante uma atitude sistemática de pesquisa que se concretiza em seus procedimentos técnico-científicos. É estranho que, no caso dos profissionais da educação, logo eles que lidam com a formação do ser humano, digam que bastam algumas horas, algum verniz, algumas disciplinas, para que se qualifiquem como profissionais (SEVERINO, 2004).

"Afinal, os problemas não se reduzem ao campo científico, mas carregam valores e aspectos sociais, éticos e culturais, o que exige uma educação em ciência e tecnologia, uma verdadeira alfabetização científica" (ROSA; TREVISAN, 2016, p. 735).

A prática da pesquisa a partir da Iniciação Científica tem sido objeto de investigação sistematizada como constatamos nos procedimentos quantitativos da Informetria aplicada na pesquisa de Costa (2013), por meio de um mapeamento amplo que "possibilitou a confirmação de que, efetivamente, o programa de IC da UFSC tem cumprido seu objetivo de contribuir com o processo de formação de pesquisadores" (COSTA, 2013, p. 168). Também observamos a pesquisa qualitativa de estudo de caso único, como na pesquisa de Melo (2003) que analisa as práticas de iniciação científica de uma aluna. "Nosso objetivo consiste em retomar a articulação do singular (o caso de Mari) com o universal (A Formação Inicial em Matemática)" (MELO, 2003, p. 188).

Ressaltamos as contribuições pedagógicas das práticas da iniciação científica nas considerações de Bridi (2010, p. 184), “entendemos que a Iniciação Científica pode ser um espaço de produção criativa com valor educativo e pedagógico". Ao encontro dessa perspectiva, podemos observar na pesquisa que avaliou as atividades acadêmicas dos egressos da Universidade Federal de Minas Gerais, que o processo de socialização acadêmica e científica dos bolsistas foi bem-sucedido, "uma vez que percorrer todos os níveis do ensino superior exige disposições pessoais e competências que se tornam cada vez mais específicas" (NOGUEIRA; CANAAN, 2009, p. 66). 
Percebemos que as competências científicas que os alunos da Iniciação Científica adquirem em suas práticas tornam-se características pessoais que definem um perfil diferenciado em sua formação, como podemos verificar na pesquisa de Jorge, Telles e Patrocino, (2010, p. 455), "nossos dados permitem afirmar que, mantidas as condições atuais, o Estado do Paraná e suas instituições estaduais de ensino superior encaminham-se para brevemente atingir níveis de excelência".

Atualmente, observa-se a necessidade de que se ampliem, linhas de pesquisa que busquem pensar a educação no ensino superior, em conexão com o ensino médio e o ensino fundamental. A formação inicial do professor pesquisador deve ser planejada e realizada na totalidade da formação do ser humano, focando o profissional que trabalha com a educação, em todos esses níveis (PIRES, 2009).

Segundo Oliveira (2010) existe o desafio de que se realize uma certa equidade em número de programas de Iniciação Científica e de alunos entre as diferentes regiões brasileiras, "trata-se de aumentar o investimento no PIBIC e programas similares, que promovam a iniciação científica não apenas na graduação, mas desde o ensino básico” (OLIVEIRA, 2010, p. 102).

Nesta pesquisa desenvolvemos um diálogo interdisciplinar em nosso referencial teórico, ao se destacar as contribuições e as correlações entre as ciências da Educação na formação de educadores: Psicologia da Educação, Filosofia da Educação e Sociologia da Educação. A partir desta idealização interdisciplinar, estabelecemos um momento de reflexão, tendo como referência os relatos de experiências dos alunos e dos professores que praticam as atividades de Iniciação Científica, os quais nos motivaram para criarmos nossas categorias de análise a saber: Aprendizagem Significativa, de acordo com Ausubel.

Aprendizagem como construção do conhecimento, conforme Severino.

$>$ A pesquisa como princípio educativo, como entendido por Demo.

Primeiramente, vamos apresentar a Universidade pesquisada e seus Programas de Incentivo à Pesquisa, focalizando as práticas dos docentes pesquisadores que identificam a valorização da formação científica dos discentes por meio da orientação aos alunos da Iniciação Científica. 


\section{Programas de Incentivo à Pesquisa da Universidade pesquisada.}

A Política de Pesquisa da universidade pesquisada valoriza as tendências das agências nacionais de fomento à pesquisa, relacionadas às suas prioridades e à alocação de recursos que apontam para a necessidade de formar docentes pesquisadores, compreendendo que o doutor é o responsável pela ciência do país. As práticas dos docentes pesquisadores já revelam que a universidade tem avançado nesse processo, haja vista as tendências em valorizar a formação científica dos discentes através da orientação a bolsistas de Iniciação Científica; em aglutinar docentes para a formação de grupos de pesquisa coordenados por doutor, envolvendo mestres e alunos de graduação e de pós-graduação; e em definir linhas de pesquisa respondendo às necessidades dos projetos pedagógicos dos cursos.

Quadro 1 - Programas de apoio à pesquisa da universidade pesquisada.

\begin{tabular}{|l|l|l|}
\hline $\begin{array}{l}\text { 1. FAPIC (Bolsa Institucional de } \\
\text { Iniciação Científica) }\end{array}$ & $\begin{array}{l}\text { 4. Política de Internacionalização da } \\
\text { Pesquisa (PROINTER) }\end{array}$ & $\begin{array}{l}\text { 7. Programa de Estímulo à } \\
\text { Formação de Pesquisadores }\end{array}$ \\
\hline 2. PIBIC / CNPq & 5. Projetos Tecnológicos (PROTEC) & $\begin{array}{l}\text { 8. Programa Professor Parceiro } \\
\text { em Pesquisa }\end{array}$ \\
\hline $\begin{array}{l}\text { 3. Política de Incentivo à Captação } \\
\text { de Recursos (PICR) }\end{array}$ & $\begin{array}{l}\text { 6. Programa de Incentivo à Produção } \\
\text { Científica (Conceito 5) }\end{array}$ & 9. Escola da Ciência \\
\hline
\end{tabular}

Fonte: adaptado dos dados do Portal da universidade pesquisada.

Destaca-se no Quadro 1, o programa de bolsa de estudo da universidade pesquisada, FAPIC, para os alunos de Iniciação Científica, assim como o programa Escola da Ciência, que é concebido como uma modalidade de excelência para o ensino, a pesquisa e a extensão de atividades científicas, compatíveis com processo didático-pedagógica dos cursos de graduação, nas mais diversas áreas de conhecimento.

\section{Processo de elaboração e explicitação das categorias de análise.}

No desenvolvimento da etapa empírica desta pesquisa, recebemos devolutivas de 20 alunos e de 15 professores que praticaram as atividades de pesquisa em projetos da Iniciação Científica. Dentre a titulação dos professores 10 são Doutores, 04 possuem Mestrado e 01 possui Pós-Doutorado. Quanto ao tempo de experiência em orientação de Iniciação Científica, 06 professores já orientaram por mais de quatro semestres, 05 professores orientaram por mais de 2 anos e 04 professores orientaram por dois semestres.

Dentre os alunos, observamos que 15 alunos pretendem continuar sua formação na PósGraduação, 03 alunos optaram por cursar outra Graduação e 02 alunos pretendem fazer outros cursos. Em tempo de experiência na prática da Iniciação Científica, são 06 alunos possuem quatro semestres de prática, 10 alunos possuem dois semestres e 02 alunos praticaram por mais 
de dois anos, 1 aluno praticou por três semestres e 1 aluno participou em um semestre. Identificamos, por meio de seus relatos escritos, as percepções vivenciadas pelos respondentes, seus desafios superados e conquistas obtidas na conclusão de seus trabalhos, configurados dentre outras possibilidades de encontros acadêmicos, nas apresentações realizadas no Encontro Anual de Iniciação Científica da instituição pesquisada. Na continuidade desse procedimento, inicialmente, compilamos todos os questionários respondidos, para a elaboração de um único texto referente à seguinte questão de natureza espontânea:

Você gostaria de relatar sua opinião sobre suas práticas de Iniciação Científica?

Para executarmos nossa análise de conteúdo, seguimos o conceito elaborado por Bardin (1977) como nossa base de análise: “Conjunto de instrumentos metodológicos cada vez mais sutis em constante aperfeiçoamento que se aplicam a discursos, extremamente diversificados" (BARDIN, 1977, p. 9). Observemos que o fator comum dessas técnicas múltiplas e multiplicadas realiza-se desde o cálculo de frequências que fornece os dados cifrados, até a extração de estruturas traduzíveis em modelos, ou seja é uma hermenêutica controlada, baseada na dedução: a inferência. Enquanto esforço de interpretação, a análise de conteúdo alterna-se entre duas orientações: da objetividade do rigor e da fecundidade da subjetividade.

Desta maneira, podemos considerar que a análise de conteúdo nos auxilia na compreensão de aspectos que possam estar escondidos, que por vezes não se identificam na aparência do texto, ou seja, procuramos pormenores que se encontram retidos por qualquer mensagem. Para que encontrássemos essa mensagem ou possíveis mensagens nas respostas dadas a nossa questão, estruturamos nossa análise em oito etapas:

1. A primeira etapa de análise constitui-se na leitura e organização dos relatos escritos, conforme Almeida e Szymanski (2002) que denominam esta primeira etapa de "Descrição ingênua" ou "Descrição I".

2. Na segunda etapa iniciamos nosso trabalho de reflexão, isto é, o trabalho intradescritivo, por meio de leituras e releituras do texto referência, para assim chegarmos ao nível da "Descrição II".

3. Na terceira etapa desse procedimento técnico de análise, originou-se um novo conteúdo teórico que se constituiu como um segundo texto, esse processo foi desenvolvido por meio de recortes ou seleções de itens emergentes extraídos da "Descrição I", estes recortes são as unidades de significados ${ }^{\mathbf{1}}$.

4. Na quarta etapa realizamos a nossa escolha subjetiva desses recortes, pautando em nosso referencial teórico e a questão inicial que motivou nossa pesquisa:

4.1 Quais contribuições as práticas de Iniciação Científica podem oferecer ao processo de ensino e aprendizagem entre alunos e professores orientadores dos 
cursos de Pedagogia e Licenciaturas, a partir das experiências em suas práticas na universidade pesquisada?

5. A quinta etapa compreendeu a elaboração de uma síntese dos recortes do texto relacionando-a ao estudo pesquisado. Nessa síntese emergiram as partes mais significativas que se direcionavam tanto ao contexto pesquisado, como ao conjunto teórico de referência. "Fazer uma análise temática consiste em descobrir os núcleos de sentido, que compõem a comunicação" (ALMEIDA; SZYMANSKI, 2002, p. 105). Esses núcleos de sentido ou unidades de significado relacionaram-se com o objetivo analítico de nossa pesquisa.

6. Na sexta etapa iniciamos um processo de categorização da síntese dos recortes. De acordo com a explicação de Almeida e Szymanski (2002), o processo de categorização concretiza a imersão dos pesquisadores nos dados e suas formas particulares de agrupálos, segundo as suas compreensões em diálogo consonante com seu referencial teórico que fundamenta sua argumentação. Essas compreensões são estruturadas a partir de domínios semânticos, em outras palavras podemos também denominar de: pontos de ancoragem. Para que encontrássemos os domínios semânticos, utilizamos a proximidade de conteúdo dos enunciados. Analisando palavras ou expressões com proximidade semântica. "É definido a priori um limiar para avaliar esta proximidade semântica. O que permite decidir se os enunciados pertencem ou não ao mesmo domínio semântico" (BARDIN, 1997, p. 219).

7. A sétima etapa corresponde ao nosso procedimento de agrupamento de domínios semânticos, esse agrupamento pautou-se na similaridade temática dos recortes, de maneira que dividimos os domínios semânticos em três temas de proximidade, isto é, dividimos os recortes direcionando-os para os temas que melhor se adequavam, haja vista que seus enunciados pertenciam ao mesmo domínio semântico.

8.1 Na oitava etapa finalizamos o processo de categorização dos recortes selecionados. Apresentamos o relato escrito dos participantes da pesquisa, destacando os domínios semânticos das palavras selecionadas que permitiram uma ancoragem de proximidade com o referencial teórico da pesquisa. Para uma compreensão didática desse processo, detalhamos cada categoria de análise e suas correlações semânticas dos termos destacados nas narrativas.

8.2 A elaboração da primeira categoria de análise:

\begin{abstract}
A dimensão formativa da IC é importante se feita em condicões e ambientes adequados e necessita de tempo. O espaço e infra e infoestrutura devem contribuir. Eu acredito que deve ser repensado o tempo de bolsa para que o aluno consiga desenvolver um projeto, publicar os resultados e abrir momentos de eventos e compartilhamento interinstitucional (Professora da IC). (Grifos nossos).
\end{abstract}

Para Ausubel (1978, p. 43): “O ensino envolve a manipulação de variáveis (fatores) que influenciam a aprendizagem, a classificação racional dessas variáveis possui um valor considerável para esclarecer a natureza e as condições que afetam o processo de aprendizagem" (Grifos nossos). Podemos observar que o autor esclarece que é muito importante considerar as condições do ambiente do ensino, o tempo a ser realizado entre outros fatores que também são ressaltados pela narrativa da professora, conforme as correlações semânticas dos termos das narrativas expostas no Quadro 2. 
Quadro 2 - Correlações semânticas dos termos das narrativas da $1^{\text {a }}$ categoria de análise.

\begin{tabular}{|l|l|}
\hline \multicolumn{1}{|c|}{ Relato da professora } & \multicolumn{1}{c|}{ Conceito de Ausubel } \\
\hline $\begin{array}{l}\text { Condições } \\
\text { Exigência. Requisa necessária e indispensável. }\end{array}$ & Afetam: Exercer influência. \\
\hline $\begin{array}{l}\text { Resultados: Ato ou efeito de resultar. Consequência. } \\
\text { Efeito. }\end{array}$ & $\begin{array}{l}\text { Aprendizagem: Ato ou efeito de aprender. Tempo } \\
\text { durante o qual se aprende. }\end{array}$ \\
\hline
\end{tabular}

Fonte: Elaboração própria.

8.3 Elaboração da segunda categoria de análise:

"Entendo a iniciação científica como fundamental para a construção do conhecimento e o pensamento crítico" (Professora da IC). (Grifos nossos).

A educação não é apenas um processo institucional e instrucional, seu lado visível, mas fundamentalmente um investimento formativo do humano, seja na particularidade da relação pedagógica pessoal, seja no âmbito da relação social coletiva. Por isso, a interação docente é considerada mediação universal e insubstituível dessa formação, tendo-se em vista a condição da educabilidade do homem (SEVERINO, 2006, p. 621). (Grifos nossos).

Destacamos no Quadro 3. As correlações semânticas dos termos das narrativas que nos auxiliam a observar que existe uma relação entre a formação educacional e humana do aluno, pois está relacionada com sua interação com o docente, sendo no caso da prática da IC, uma das formas essenciais para a sua construção do conhecimento e do seu pensamento crítico.

Quadro 3 - Correlações semânticas dos termos das narrativas da $2^{\text {a }}$ categoria de análise.

\begin{tabular}{|l|l|}
\hline \multicolumn{1}{|c|}{ Relato da professora } & \multicolumn{1}{c|}{ Conceito de Severino } \\
\hline $\begin{array}{l}\text { Fundamental: Que serve de fundamento. Essencial, } \\
\text { principal. }\end{array}$ & $\begin{array}{l}\text { Fundamentalmente: Que serve de fundamento. } \\
\text { Essencial, principal. }\end{array}$ \\
\hline $\begin{array}{l}\text { Crítico: Que ou quem critica, analisa. } \\
\text { Pensamento: Ato ou efeito de pensar. Conhecer. } \\
\text { Formação. Saber. }\end{array}$ & $\begin{array}{l}\text { Educabilidade: Qualidade de educável. Aptidão para se } \\
\text { educar. }\end{array}$ \\
\hline
\end{tabular}

Fonte: Elaboração própria.

8.4 Elaboração da terceira categoria de análise:

Ao participar da IC no segundo semestre de minha graduação, pude abrir horizontes em relação à pesquisa. Adquiri novos conhecimentos e novas formas de utilizar o saber e de aplicá-los diariamente em minha nova profissão. Despertou em mim o interesse de não me acomodar com o já existente, mas sim em sempre buscar novas alternativas (Aluna da IC). (Grifos nossos).

Segundo Demo (1994, p. 95): “A meta é clarividente: forjar gente construtiva e participativa, capaz de projeto moderno e próprio de desenvolvimento humano sustentado". Identificamos a relação semântica entre as palavras utilizadas pela aluna e o referencial teórico de nossa pesquisa. As práticas da pesquisa incentivam o desenvolvimento humano criativo, inovador e participativo, conforme o Quadro 4. 
Quadro 4 - Correlações semânticas dos termos das narrativas da $3^{\text {a }}$ categoria de análise.

\begin{tabular}{|l|l|}
\hline \multicolumn{1}{|c|}{ Relato da aluna } & \multicolumn{1}{c|}{ Conceito de Demo } \\
\hline $\begin{array}{l}\text { Novo: Ato de inovar - Introduzir novidades em. Renovar. } \\
\text { Inventar. Criar. }\end{array}$ & $\begin{array}{l}\text { Moderno: Que tem ou contém progressos recentes da } \\
\text { ciência e da tecnologia. }\end{array}$ \\
\hline $\begin{array}{l}\text { Conhecimentos: Ato ou efeito de conhecer. Formação. } \\
\text { Saber. }\end{array}$ & $\begin{array}{l}\text { Desenvolvimento: Ato ou efeito de desenvolver. Fazer } \\
\text { crescer; aumentar as faculdades intelectuais de alguma } \\
\text { pessoa. }\end{array}$ \\
\hline
\end{tabular}

Fonte: Elaboração própria.

O resumo da oitava etapa pode ser observado no Quadro 5., com o conjunto de unidades de significados que extraímos, tendo como referência de elaboração os relatos de experiências dos alunos e dos professores da IC. Esse processo permitiu uma reflexão de três temas, em outras palavras, de três categorias de análise:

Quadro 5 - Processo de elaboração das categorias de análise.

\begin{tabular}{|c|c|c|c|}
\hline Narradora & Relatos escritos & $\begin{array}{l}\text { Explicitação dos } \\
\text { significados }\end{array}$ & Categoria de análise \\
\hline $\begin{array}{l}\text { Professora orientadora } \\
\text { de IC }\end{array}$ & $\begin{array}{l}\text { A dimensão formativa da IC } \\
\text { é importante se feita em } \\
\text { condições e ambientes } \\
\text { adequados e necessita de } \\
\text { tempo. O espaço e infra e } \\
\text { infoestrutura devem } \\
\text { contribuir. Eu acredito que } \\
\text { deve ser repensado o tempo } \\
\text { de bolsa para que o aluno } \\
\text { consiga desenvolver um } \\
\text { projeto, publicar os } \\
\text { resultados e abrir momentos } \\
\text { de eventos e } \\
\text { compartilhamento } \\
\text { interinstitucional. }\end{array}$ & $\begin{array}{l}\text { Existe a necessidade de } \\
\text { que aconteça uma } \\
\text { interação entre os fatores } \\
\text { que influenciam a } \\
\text { aprendizagem como: } \\
\text { material significativo, } \\
\text { condições adequadas do } \\
\text { ambiente de ensino, } \\
\text { tempo, estrutura cognitiva } \\
\text { particularizada etc., para } \\
\text { que o aluno apresente } \\
\text { uma atitude de } \\
\text { aprendizagem } \\
\text { significativa. }\end{array}$ & $\begin{array}{l}\text { 19 categoria } \\
\text { A aprendizagem } \\
\text { Significativa na } \\
\text { formação de educadores }\end{array}$ \\
\hline Narradora & Relatos escritos & $\begin{array}{l}\text { Explicitação dos } \\
\text { significados }\end{array}$ & Categoria de análise \\
\hline $\begin{array}{l}\text { Professora } \\
\text { Orientadora de IC }\end{array}$ & $\begin{array}{l}\text { Entendo a iniciação } \\
\text { científica como fundamental } \\
\text { para a construção do } \\
\text { conhecimento e o } \\
\text { pensamento crítico. }\end{array}$ & $\begin{array}{l}\text { A Iniciação Científica é } \\
\text { uma aprendizagem prática } \\
\text { e teórica que encaminha o } \\
\text { aluno à sua autonomia. }\end{array}$ & $\begin{array}{l}2^{\text {a }} \text { categoria } \\
\text { A aprendizagem como } \\
\text { construção de } \\
\text { conhecimento. }\end{array}$ \\
\hline Narradora & Relatos escritos & $\begin{array}{l}\text { Explicitação dos } \\
\text { significados }\end{array}$ & Categoria de análise \\
\hline Aluna de IC & $\begin{array}{l}\text { Ao participar da IC no } \\
\text { segundo semestre de minha } \\
\text { graduação, pude abrir } \\
\text { horizontes em relação à } \\
\text { pesquisa. Adquiri novos } \\
\text { conhecimentos e novas } \\
\text { formas de utilizar o saber e } \\
\text { de aplicá-los diariamente em } \\
\text { minha nova profissão. } \\
\text { Despertou em mim o } \\
\text { interesse de não me } \\
\text { acomodar com o já } \\
\text { existente, mas sim em } \\
\text { sempre buscar novas } \\
\text { alternativas. }\end{array}$ & $\begin{array}{l}\text { As práticas de pesquisa } \\
\text { incentivam à inovação e } \\
\text { criação de novos } \\
\text { conhecimentos. }\end{array}$ & $\begin{array}{l}3^{\text {a categoria }} \\
\text { A pesquisa como } \\
\text { princípio educativo }\end{array}$ \\
\hline
\end{tabular}

Fonte: Adaptado de: ALMEIDA, Laurinda Ramalho de; SZYMANSKI, Heloisa. A entrevista na pesquisa em educação: a prática reflexiva. Brasilia: Editora Plano, 2002. 


\title{
A primeira categoria de análise: a aprendizagem significativa na formação de educadores
}

Escolhemos como o início de nossa primeira categoria de análise a reflexão sobre alguns desafios da prática da pesquisa, enunciados nas narrativas das professoras 1 e 2 apresentadas seguidamente:

\begin{abstract}
Gostaria de lhe dizer que as contribuições das práticas de Iniciação Científica na formação de educadores, nas instituições de educação superior brasileiras, são importantes, mas, também, um reflexo da educação vigente na atualidade. Ou seja, temos uma educação que ainda está longe do paradigma "educar pela pesquisa" (Demo), ou daquele outro que acredita que a pesquisa é parte constitutiva da educação (Freire) (Professora 1).
\end{abstract}

Na prática de orientação de Projetos de Iniciação Científica tenho encontrado dificuldade em relação ao tempo de dedicação dos estudantes por serem, estes, alunos-trabalhadores. A maior parte das orientações se dá a distância, o que, no meu ponto de vista, parece empobrecer o processo (Professora 2)

Conforme as palavras das professoras podemos conceber que um concernente caminho que sobreleve a formação de educadores ao nível adequado de qualidade formativa, perpassa pela oportunidade de que alunos e professores efetivem e pratiquem uma aprendizagem significativa. Porque a aprendizagem significativa compreende que o desenvolvimento do significado do conhecimento para o estudante, necessita de que em suas atividades de aprendizagem, possa ser motivado a participar ativamente, a fim de que seja capaz de construir e reestruturar seu novo conhecimento, articulando-o com suas próprias palavras.

São muitas as dificuldades apresentadas na educação superior, isto é, a) as defasagens de conhecimentos prévios que deveriam ser desenvolvidos na educação básica, que se tornam entraves para a aprendizagem, pois são conhecimentos necessários e prévios que baseiam os novos conhecimentos; b) a carga horária de trabalho do professor e do aluno, que precisa ser equilibrada com uma série de atividades acadêmicas; c) a necessidade de infra estrutura das instituições de ensino, como laboratórios de informática, salas de estudos com recursos midiatizados, bibliotecas atualizadas etc., entre outros diversificados desafios apresentados atualmente.

A maior dificuldade que tenho na prática da Iniciação Científica é o fato dos alunos necessitarem
trabalhar muitas horas por semana, realizar o curso de graduação, e, ainda, 'cobertos' pela "bolsa",
necessitarem assumir projetos de pesquisa sob a orientação de um professor (que por vezes está na
mesma situação que o aluno com relação à sobrecarga de horas de trabalho) o que implica mais horas
de dedicaça para a leitura, o estudo identificando as metodologias de pesquisa, o pensamento criativo
e crítico do conhecimento (Professora 1). A Iniciação Científica fica mais enriquecida com encontros presenciais, ao invés de encontros virtuais e quanto maior a disponibilidade do aluno e do professor, melhor é o seu aproveitamento (Professor 3).

Dentro desse contexto apresentado pelas narrativas dos docentes, identificamos um diálogo consonante com as devolutivas estatísticas dos discentes, porque na divisão de alunos por escolha relacionada ao tema de projeto da Iniciação Científica, identificou-se que a maioria 
prefere que os projetos de pesquisa se relacionassem aos conteúdos estudados no decorrer da graduação, pois esse aspecto tanto auxilia na administração de seus estudos, trabalho e vida pessoal, da mesma forma que incorporam aos estudos teóricos da graduação aspectos substanciais que permitem uma aprendizagem mais significativa.

\begin{abstract}
A prática de iniciação científica contribui de forma significativa para a minha vida profissional. Através dos estudos realizados, pude comprovar na prática o que aprendi na teoria (Aluna 1 - Graduação em Pedagogia)

Seu orientador é sua referência (o que ler, o que/como escrever, por onde começar...) uma letra indispensável em cada linha de sua pesquisa, pois é seu parceiro de estudos e troca de ideias que não deixa de ser além de professor um aluno que ali juntamente com você aprende um pouco mais, transmitindo e dividindo saberes, orientando em leituras e posicionando suas letras nas linhas corretas para que o artigo não fuja do contexto da pesquisa (Aluna 2 - Graduação em Pedagogia).
\end{abstract}

Podemos verificar nas percepções das alunas, como se faz necessário atender aos dois aspectos fundamentais da Aprendizagem Significativa, ou seja, seu significado lógico e seu significado psicológico. Quando nos referimos ao significado lógico devemos compreender como a natureza do material e dos recursos utilizados pelo educador que se relacionem com as condições do aprendiz.

“Acredita-se que o educador, possuindo um conjunto de princípios psicológicos, aplicáveis à sua prática, possa encontrar soluções para os problemas que surgem, levando em conta a relevância de tais proposições” (ARAGÃO, 1976, p. 101). Os princípios psicológicos válidos para a prática educacional, não somente propiciam novas propostas de ensino, como também eliminam ou evitam muitas das práticas ineficazes.

Enquanto que, ao nos referirmos ao significado psicológico, precisamos compreender que existe uma relação profunda entre a estrutura lógica e a estrutura psicológica do conhecimento e assim sendo é importante considerar fatores como a sensibilidade e a motivação do aluno, para que seja incentivado a desenvolver a sua capacidade de construir e reconstruir sua aprendizagem. Essa reconstrução pode ser observada, quando o aluno compreende a existência de relações e interações entre significados e nexos, até que se tornem relações estáveis, desta maneira o aluno constrói gradativamente seu conhecimento. Desta forma, é muito importante entender que a aprendizagem é significativa quando o "conhecimento prévio (conceito, ideia, proposição) servirá de ancoradouro para o novo conhecimento" (MOREIRA, 2003, p. 19). Os novos conhecimentos passam a significar algo para o aprendiz, quando ele ou ela é capaz de explicar situações com suas próprias palavras, quando é capaz de resolver problemas novos, enfim, quando compreende. "Saber explicar usando significados aceitos, mas matizando-os com interpretações pessoais está na essência da aprendizagem significativa" (MOREIRA, 2003, p. 41). 
A Pedagogia é arte e a ciência de apresentar ideias e informações de uma maneira significativa, de modo que apresentem significados claros, estáveis e inequívocos e que sejam retidos durante um período de tempo consideravelmente largo, em forma de um corpo organizado de conhecimento, "en realidad es la principal función de la pedagogía” (AUSUBEL, 2002, p. 97).

Outra possibilidade acontece por alunos mestres ou doutorandos que já lecionam na graduação e podem desenvolver projetos próprios de pesquisa de Iniciação Científica. Essas duas possibilidades, tanto podem alavancar a qualidade da formação dos futuros educadores, como incentivam os professores a estarem em contínua atualização por intermédio dos projetos de pesquisa, uma vez que as atividades de pesquisa são fatores motivacionais à elaboração de novas bibliografias, entre outras formas de uso da pesquisa como princípio educativo. “Ordinariamente, pois, aprendizagem e retenção querem dizer prática. Esta, além de tudo, é sempre específica (restringida a tarefa da aprendizagem) e deliberada (intencional)" (AUSUBEL; NOVAK; HANESIAN, 1980, p. 319).

Acredito que a IC tem contribuído para que os alunos da graduação compreendam melhor o sentido da Pós-Graduação Stricto Sensu e da pesquisa científica. Um dos principais desafios que encontramos nestes anos foi o distanciamento entre a Graduação e o PPGE nos casos, como o meu, em que os orientadores e co-orientadores não dão aulas na Graduação (Doutoranda/co-orientadora).

A partir das colocações supracitadas da doutoranda, podemos observar a importância da intencionalidade e do sentido da pesquisa científica, pois para os psicólogos, a intencionalidade da consciência deve ser tomada em termos de atos: o significado de ver só existe quando há algo para ser visto. "O ato da consciência coloca o indivíduo diante do objeto em busca de sua identidade ou sua identificação" (MOREIRA, 1982, p. 2). Esse sentido se concretiza na mediação pedagógica entre orientador e aluno, porque consideramos que a aprendizagem é um processo de construção do conhecimento.

\section{Segunda categoria de análise: a aprendizagem como construção de conhecimento}

Tendo como referência as palavras da professora 4, apresentadas a seguir, precisamos nos questionar se todo esse conhecimento científico que possuímos traz algo de favorável ou, pelo contrário, desfavorável para a nossa vida.

A Iniciação Científica deveria ser mais incentivada, pois contribui para o avanço nas pesquisas e no avanço na ciência (Professora 4). 
"Tal como noutros períodos de transição, difíceis de entender e de percorrer, é necessário voltar às coisas simples, à capacidade de formular perguntas simples" (SANTOS, 1990, p. 6). O privilégio de desfrutar do tempo de encontros presenciais, de discussões e questionamentos, das trocas de experiências, do aprofundamento em leituras, da possibilidade de elaborarmos as nossas perguntas, que mesmo ao serem simples, sabemos que suas respostas certamente não o serão, porque entremeada a certa ordem científica, situa-se a subjetividade humana. Essa relação subjetiva se realiza no estabelecimento de vínculos entre os alunos e o professor, tendo em vista que o aluno se desenvolve e o professor se atualiza constantemente.

"A ignorância de tudo o que faz o "ar do tempo" produz por si mesma uma perda das relações das obras com a realidade, as quais, encontrando-se despojadas daquilo que as ligava aos mais concretos debates de seu tempo" (BOURDIEU, 2007, p. 32). Este aspecto nos introduz ao pensamento de que as conotações das palavras podem se transformar no decorrer dos momentos históricos, pois o sentido e o valor de uma determinada palavra ou expressão sofre um empobrecimento e uma transformação no sentido do intelectualismo ou de humanismo vazio. Assim, a pesquisa precisa estar atrelada e contextualizada ao nosso tempo cotidiano, para fazermos paralelos entre os acertos e contrapontos dos fatos.

Nunca é demais repetir que a finalidade da educação é a humanização, a formação das pessoas humanas, e mais do que qualquer outra prática social, cabe a ela, nessa condição, investir na construção da autonomia das pessoas, respeitando e consolidando sua dignidade. “Trata-se da própria construção do humano que não é dado como pronto e acabado, mas como um ser a ser construído, num processo permanente de um vir a ser, de um tornar-se humano" (SEVERINO, 2014, p. 207), podemos observar alguns aspectos dessa formação humana nas palavras da aluna 4 , logo abaixo:

\begin{abstract}
A práxis adquirida com a Iniciação Científica, possibilitou que se manifestasse meu gosto latente pela pesquisa, o que eu senti sobrepujar as minhas expectativas como futura professora licenciada em História. E quando digo práxis adquirida, refiro-me às inúmeras leituras que tive que realizar, os fichamentos, os comentários sobre a bibliografia, as pesquisas "in loco" que me levaram a Assunção no Paraguai, as entrevistas com autoridades do Ministério da Cultura daquele país, do Departamento de Patrimônio, dos museus e bibliotecas, das universidades, etc. Com a experiência adquirida, ficou mais fácil desenvolver as atividades de pesquisa referentes ao TCC e mesmo para outros trabalhos que meus Mestres orientavam no decorrer do curso (Aluna 4 - Licenciatura em História)
\end{abstract}

"Todo o conhecimento é local e total" (SANTOS, 1990, p. 46), em outras palavras o conhecimento baseia-se em temas que são adotados por grupos sociais concretos como projetos de vida locais. A fragmentação pós-moderna não é disciplinar, mas sim temática. "Todo o conhecimento científico visa constituir-se em senso comum” (SANTOS, 1990, p. 55). Com esta tese o autor afirma, basicamente, que a ciência pós-moderna deve dialogar com outras formas 
de conhecimento, em particular com o conhecimento do senso comum. Deste modo, considerase que "tal como o conhecimento se deve traduzir em autoconhecimento, o desenvolvimento tecnológico deve traduzir-se em sabedoria de vida" (SANTOS, 1990, p. 57), num saber prático, que ensina a viver, para que seja naturalizado e significativo.

"A dignidade da pessoa é o critério para a leitura avaliativa das ações mediante as quais se constrói a história real” (SEVERINO, 2009, p. 159). A história cotidiana é construída e realizada em nossa vida em sociedade. A nossa sabedoria de vida é adquirida por meio de nossa autonomia de construir nosso conhecimento, com o objetivo de pensarmos e raciocinarmos sobre nossa condição e participação histórica e social. "O conhecimento tem sempre um caráter de classe, é sempre um conhecimento de classe. Por isso, ele tem na posição de classe do sujeito que conhece uma condição necessária (mas não suficiente) da verdade” (CUNHA, 1984, p. 18).

Ao participar desse programa fomentamos de forma crítica e reflexiva, parâmetros para aprofundarmos e enriquecermos a nossa vida acadêmica e beneficiarmos de maneira significativa o âmbito social ao qual vivenciamos. Atualmente estou encerrando a minha Pós-graduação (Lato-senso) e já fiz a minha inscrição para o Programa de Mestrado. E um dos fatores que me proporcionaram nitidamente um embasamento teórico foi Artigo Científico que desenvolvi durante a Graduação. Essas práticas contribuem qualitativamente para ampliarmos e aprimorarmos nossa ótica a respeito de questões que permeiam a proposta que pretendemos pesquisar em nosso trabalho (Aluna 5 - Graduação em Pedagogia).

Os relatos das alunas, identificam a amplitude e a diversificada aprendizagem adquirida na prática da IC, porque se realiza desde as experiências de suas leituras às pesquisas de campo, na possibilidade de conhecer novos contextos culturais e acadêmicos. Suas formações na graduação tornaram-se integradas ao "gosto latente pela pesquisa", culminado na naturalidade da elaboração de Trabalho de Conclusão de Curso e de artigo científico. De acordo com Severino (2012, p. 112), "Estabelecer um estatuto de cientificidade para o campo educacional exige uma profunda reconceituação de ciência. Isso se deve ao caráter práxico da educação, por ser ela uma prática intencionalizada". A existência e a realidade da Educação se justificam porque ela é uma intervenção social que constrói sujeitos.

Trabalhar com alunos interessados em aprender a fazer pesquisa, a desenvolver um projeto até o final, é muito gratificante tanto para o aluno como para o professor. Percebo que os alunos de IC são mais atentos em sala de aula e mais interessados em aprender sobre os conteúdos das diversas disciplinas da graduação. O crescimento acadêmico é visível, outros professores percebem que estes alunos se destacam em sala de aula. No final, o aluno é quem aprende. E isto é muito bom, pois me dá um sentimento de dever cumprido (Professora 5).

A Iniciação Científica auxiliou em meu desempenho na Graduação e até mesmo possibilitou que eu ajudasse minhas colegas de classe. Os conteúdos pesquisados relacionam-se com o curso e nos permitem ir além da sala de aula. Em relação à pesquisa, quando temos a oportunidade de iniciar no campo da pesquisa durante a graduação, percebemos e aprendemos sobre o quão significativo é em nossa área (Aluna 6 - Graduação em Pedagogia). 
Destacamos nos pensamentos da professora e da aluna, que o desempenho na graduação se vincula ao equilíbrio entre a teoria e a prática. "No plano da pesquisa, precisamos trabalhar com a teoria teorizante e não com a teoria teorizada" (SEVERINO, 1999, p. 32). Por assim dizer, o estudo teórico/científico precisa ser praticado e elaborado, por meio de diálogos reflexivos e analíticos, entre o aluno e professor mediante suas percepções do objeto de estudo, a partir de seus contextos históricos e sociais.

\title{
A terceira categoria de análise: a pesquisa como princípio educativo
}

O pensamento de que os alunos desde os primeiros semestres desenvolvam um estilo de vida construtivo e participativo é concernente com Demo (2001, p. 17), “pesquisa é processo que deve aparecer em todo trajeto educativo, como princípio educativo que é, na base de qualquer proposta emancipatória".

Desta maneira, ressaltamos que: "É essencial arquitetar condições favoráveis ao aprender a aprender, desde o primeiro dia, incentivando aos alunos: atitude de pesquisa, autonomia crítica, busca criativa, evolução qualitativa" (DEMO, 1994, p. 109).

\begin{abstract}
A Iniciação Científica só me fez ter certeza de que é necessário pesquisar sobre aquilo que queremos trabalhar ou desenvolver, reaprendi a estudar, tive contato com opinióes que eram a meu favor e contra mim, contra o que penso, isso fez com que eu reconsiderasse alguns pontos, buscasse outras respostas. Aprendi a lançar um novo olhar para meus projetos e aceitar as decepções como experiências (Aluna 7 - Graduação em Pedagogia).
\end{abstract}

Sublinhamos que, no relato da aluna 7, as suas aprendizagens não são recebidas passivamente. "Cada um só poderá saber o que o levou a experiências satisfatórias ou angustiantes se for capaz de retomar as situações sem que essas experiências ocorreram; se conseguir resgatar com clareza os momentos nos quais o que acontecia foi sentido" (MASINI, 2008, p. 110). A experiência vivenciada pelo aluno, constitui-se numa realidade percebida e compreendida, porque incluímos a nossa própria ação desencadeada nessas situações. Na especificidade do aluno de Iniciação Científica é imprescindível a presença de seu orientador, para que o auxilie a desvendar essas situações confusas, de maneira que supere qualquer sentimento de paralisação, de não conseguir poder usufruir do próprio potencial na continuidade do processo de aprendizagem.

Participar das práticas de Iniciação Científica foi uma experiência enriquecedora. As pesquisas ajudavam em momentos de socialização e discussões de temas em sala de aula, na graduação, bem como na aquisição de uma escrita mais trabalhada, compreensível e sucinta. Com a realização do projeto de pesquisa, pude ter mais clareza sobre o que é e a importância de um mestrado. Pretendo seguir meus estudos e, compreendo que a IC é algo fundamental, uma base para um entendimento do processo de 
pesquisas, uma vez que ela (Iniciação Científica) é uma prévia dos procedimentos necessários para a realização de uma Pós-Graduação, em especial a Stricto Senso (Aluna 8-Pedagogia).

Frisamos nas considerações da aluna 8 que a aproximação e a troca de experiências entre a aluna e seu orientador são fundamentais, haja vista que para construir o novo conhecimento, o aluno precisa atingir a maturidade cognitiva. Esse processo de autoconhecimento é um desafio que pode ser superado, assim como se efetiva na autonomia intelectual do aprendiz. "Aprender a aprender e saber pensar, para intervir de modo inovador, são as habilidades indispensáveis do cidadão e do trabalhador modernos, para além dos meros treinamentos, aulas, ensinos, instruções etc.” (DEMO, 2011, p. 9).

\begin{abstract}
Consideramos que as atividades de IC foram válidas e tivemos a oportunidade de trabalhar um tema de interesse em particular (Educação \& Cidadania). No TCC, desenvolvemos um tema correlato, de modo que as reflexões feitas durante a IC foram bem aproveitadas. Os trabalhos da IC, entretanto, ficaram bastante prejudicados, devido às poucas reuniões realizadas com o grupo, à demora para a distribuição de tarefas e prazos, e sobretudo à falta de comprometimento na realização das propostas elou abandono por parte de vários alunos envolvidos no projeto. Desse modo, os alunos que se apresentaram mais ativos na IC, acabaram sobrecarregados com as tarefas e alguns inclusive sentiram-se desestimulados. Ressalto positivamente a experiência, apesar desses contratempos, desejando que aconteçam os ajustes necessários e que novas medidas de organização sejam adotadas para o prosseguimento da IC (Aluno 9 - Licenciatura em Ciências Sociais).

Desde o primeiro semestre quis me engajar em uma IC. A princípio participaria de uma sobre a Pedagogia Waldorf, mas pelo que pareceu a professora não quis dar continuidade (o que também aconteceu com vários colegas meus). Então, com base em um tema que gostaria de abordar (contratos pedagógicos) busquei algum docente com boa vontade para patrocinar a minha ideia. Comecei a minha pesquisa no final do segundo semestre. O fato de ser normalista (fiz magistério) me ajudou bastante quanto à exploração da bibliografia. Foi uma experiência muito enriquecedora, tanto que agora já estou me preparando para o mestrado. Percebi que acabei ficando academicamente mais maduro do que os meus pares (Aluno 10 - Graduação em Pedagogia).
\end{abstract}

Pelas experiências dos dois alunos supracitados, constatamos que toda prática é uma superação de desafios, à medida que concebemos e propomos um planejamento de projeto de pesquisa, necessitamos ter antecipadamente a coerência de que seu planejamento seja flexível aos percursos de sua realização. A relevância dos relatos e das experiências vivenciadas pelos alunos podem ser uma base de dados dos desafios práticos da execução de um projeto, pois já possuem certa maturidade científica dos possíveis reveses que ocorrem no transcorrer dos estudos: administrar o tempo, o apoio dos participantes ou entrevistados, da coleta e análise de dados, entre outros aspectos que compreendemos somente quando desenvolvermos uma pesquisa. "A qualidade da universidade depende também de apoios didáticos fundamentais, que facilitam a vida produtiva" (DEMO, 1994, p. 111).

Destacamos a biblioteca sempre atualizada e os laboratórios de informática com acesso aos principais portais de pesquisa. Dizemos em metodologia que todo dado é um construto. Também o dado empírico é um construto, resultado de múltiplas determinações teóricas e 
ideológicas (DEMO, 2012, p. 32). O autor completa seu pensamento, salientando como fundamental a criação de caminhos da multidisciplinaridade e da pesquisa matricial, bem como o trabalho em equipe, rompendo o isolamento dos atuais cursos e a distância entre os professores. Os projetos interdisciplinares ou projetos de extensão são exemplos de possibilidades didáticas que incentivam a comunicação e trocas de conhecimentos de profissionais em áreas diversificadas. "É preciso lembrar que, em termos metodológicos, pesquisa é procedimento cercado de rigores lógico-formais mais ou menos típicos, sendo impróprio aplicar o conceito a qualquer coisa" (DEMO, 2008, p. 105).

O estudante de Iniciação Científica aprende a construir um artigo científico, a fazer uma resenha crítica e amplia substancialmente os seus horizontes no âmbito da literatura científica. Afinal, aprende a fazer pesquisa que é esse o objetivo da Iniciação Científica (professor 6).

A Iniciação foi algo de suma importância para meu aprendizado e decisões sobre meu futuro. Gostaria de poder participar de outros projetos da Universidade (Aluno 11 - Graduação em Educação Física).

As considerações do aluno 11 sublinham que as experiências na IC puncionam os praticantes às demais atividades acadêmicas, como a participação de grupos de pesquisa, nos projetos de extensão, aos encontros e eventos científicos da Universidade, como colóquios, congressos e palestras. Quaisquer mudanças a serem desenvolvidas no campo educacional não deveriam ser isoladas ou momentâneas, realizadas somente em eventos, solenidades, dia da ciência e tecnologia, sem se raciocinar sobre o fato de que o sistema educacional ainda carece da cultura de educação científica. "Educação científica abriga, assim, a pretensão forte de motivar um salto de qualidade nos processos escolares de aprendizagem. Em particular, pretende-se refazer, por completo, de alto a baixo, a formação docente" (DEMO, 2014, p. 16).

A pesquisa como princípio educativo visa contribuir para a inserção da cultura da cientificidade e da construção do conhecimento autônomo na Educação brasileira.

\section{Considerações Finais: por Uma Didática Renovada no Ensino Superior}

Cada aluno possui sua história de vida particularizada. Em nossa pesquisa os alunos respondentes caracterizaram-se como alunos da graduação, atuantes em atividades profissionais, participantes como pesquisadores nas atividades de Iniciação Científica e da PósGraduação, de maneira que conseguem equilibrar a dicotomia entre trabalho intelectual e suas práticas profissionais cotidianas, aspecto que demonstra a maturidade quanto aos desafios de manter uma dedicação à produção científica e às horas de docência.

A oportunidade de estar próximo ou distante se realiza nas diversificadas maneiras de o ser humano relacionar-se com outro ser humano. "Heidegger chama de solicitude, que indica 
as características básicas de ter consideração e de ter paciência para com o outro" (MASINI, 2008, p. 70). A autora também apresenta que outra maneira de “cuidado com outro' é colocarse diante do outro, propiciando que este assuma seus próprios caminhos, cresça, amadureça e encontre-se consigo mesmo.

Observamos que nas práticas da IC os alunos conseguiram desenvolver suas próprias habilidades de aprender e de lidar com suas dificuldades, essa experiência tornou-se uma forma de Aprendizagem Significativa. "A educação não é apenas um processo institucional e instrucional, seu lado visível, mas fundamentalmente um investimento formativo do humano, seja na particularidade da relação pedagógica pessoal, seja no âmbito da relação social coletiva" (SEVERINO, 2006, p. 621). Considerada a amplitude da educação, centralizamos a interação docente na prática educativa, porque essa interação é essencial para a mediação universal e insubstituível dessa formação, tendo-se em vista a condição da educabilidade humana. A necessidade da prática do filosofar situa-se na inovação e na criação, as quais dependem da autoria, oriunda da intrínseca autonomia do pensar, ou seja, de se saber pensar. Uma vez que a existência humana se encaminha em sentidos, na atitude de refletir que é um exercício da busca de sentidos. A intersubjetividade das relações humanas entre os alunos e o professor orientador permite uma reflexão sobre o sentido do conhecimento para o existir humano, como também conduz à conscientização e ao esclarecimento crítico dos aspectos ideológicos que determinam axiologicamente o conhecimento, como produto estancado e fragmentado.

A universidade é um dos espaços públicos em que privilegiadamente podem e devem vicejar as reflexões, os conhecimentos e técnicas, em clima de normal aceitação das contradições, das diferentes visões de mundo, da liberdade de pensamento e de criação. Formação e conhecimento com qualidade científica e pertinência social se entrelaçam na concretização da responsabilidade pública da universidade (DIAS SOBRINHO, 2015). A educação precisa estar centrada na relação inseparável do educador e seu educando, porque a necessidade da existência de um, depende da existência do outro. Analise-se, na existência e na convivência de trocas de conhecimentos, para que aconteçam possibilidades de transformação de um ensino reprodutor de ideias para um processo de ensino aprendizagem criador que seja libertador da realidade desigual, histórica, social, econômica e política da sociedade moderna.

\section{Referências}

ALMEIDA, Laurinda Ramalho de; SZYMANSKI, Heloisa. A entrevista na pesquisa em educação: a prática reflexiva. Brasilia: Editora Plano, 2002. 
ARAGÃO, Rosália Maria Ribeiro de. Teoria da aprendizagem significativa de David P. Ausubel. Sistematização dos aspectos teóricos fundamentais. 109 f. 1976. Tese (Doutorado) Faculdade de Educação, UNICAMP, Campinas, 1976.

AUSUBEL, David Paul. Psicología educacional: un punto de vista cognoscitivo. México: Editorial Trillos, 1978.

AUSUBEL, David Paul. Adquisicion y retencion del conocimiento. Una perspectiva cognitiva. Barcelona: Ediciones Paidós Ibérica, 2002.

AUSUBEL, David Paul; NOVAK, Joseph D.; HANESIAN, Helen. Psicologia educacional. Rio de Janeiro: Interamericana, 1980.

BARDIN, Laurence. Análise de conteúdo. Lisboa: Edições 70, 1977.

BRIDI, Jamile Cristina A., A pesquisa na formação do estudante universitário: a Iniciação Científica como espaço de possibilidades. 214 f. 2010. Tese (Doutorado) Programa de Pós-Graduação em Educação, Universidade de Campinas, Campinas, 2010.

BOURDIEU, Pierre. As ciências sociais e a filosofia. Revista Educação \& Linguagem, São Paulo, n. 16, p. 1- 219, 2007.

COSTA, Airton. O processo de formação de pesquisadores: análise do programa de iniciação científica da Universidade Federal de Santa Catarina no período de 1990 a 2012. 204 f. 2013. Dissertação (Mestrado) - Programa de Pós-Graduação em Ciência da Informação, Universidade Federal de Santa Catarina, Florianópolis, 2013.

CUNHA, Luís Antônio. Diretrizes para o estudo histórico do ensino superior no Brasil. Revista Em Aberto, Brasília, n. 3, set./out. 1984.

DIAS SOBRINHO, José. Universidade fraturada: reflexões sobre conhecimento e responsabilidade social. Avaliação, Campinas; Sorocaba, v. 20, n. 3, nov. 2015.

DEMO, Pedro. Educação e qualidade. Campinas: Papirus, 1994.

DEMO, Pedro. Educar pela pesquisa. 7. ed. Campinas: Autores Associados, 2001.

DEMO, Pedro. Pesquisa participante, saber pensar e intervir juntos. Brasília: Liber Livro, 2008.

DEMO, Pedro. Pesquisa: princípio científico e educativo. 14. ed. São Paulo: Cortez, 2011.

DEMO, Pedro. Pesquisa e informação qualitativa, aportes metodológicos. 5. ed. Campinas: Papirus, 2012.

DEMO, Pedro. Educação Científica. Revista Brasileira de Iniciação Científica, Itapetininga, v. 1, n. 1, maio 2014.

JORGE, Marcos; TELLES, Tiago; PATROCINO, A. C. A iniciação científica no ensino superior. Rev. Diálogo Educ., Curitiba, v. 10, n. 30, p. 441-457, maio/ago. 2010.

MASINI, Elcie F. Salzano; MOREIRA, Marco Antonio. Aprendizagem significativa: condições para ocorrência e lacunas que levam a comprometimentos. São Paulo: Vetor, 2008.

MELO, Gilberto Francisco Alves de. A formação inicial e a iniciação científica: investigar e produzir saberes docentes no ensino de álgebra elementar. 253 f. 2003. Tese (Doutorado) Universidade Estadual de Campinas, Campinas, 2003.

MOREIRA, Marco Antonio; MASINI, Elcie F. Salzano. Aprendizagem significativa: a teoria de David Ausubel. São Paulo: Moraes, 1982. 
MOREIRA, Marco Antonio. Linguagem e Aprendizagem Significativa. Instituto de Física da UFRGS. In: ENCONTRO INTERNACIONAL LINGUAGEM, CULTURA E COGNIÇÃO, 2., 2003, Belo Horizonte, 2003.

NOGUEIRA, Maria Alice; CANAAN, Mariana Gadoni. Os "Iniciados": os bolsistas de iniciação científica e suas trajetórias acadêmicas. Rev. Tomo, São Cristóvão, n. 15, p. 41-70, jul./dez. 2009.

PIRES, Regina Celi. M. Formação inicial do professor pesquisador através do programa PIBIC/CNPq: o que nos diz a prática profissional de egressos? Avaliação, Campinas; Sorocaba, v. 14, n. 2, jul. 2009.

SANTOS, Boaventura de Sousa. Um discurso sobre as ciências. 4. ed. Porto: Afrontamento, 1990.

SEVERINO, Antônio Joaquim. Novos enfoques da pesquisa educacional. In: FAZENDA, Ivani (Org.). Novos enfoques da pesquisa educacional. São Paulo: Cortez, 1999.

SEVERINO, Antônio Joaquim. Dialogia, São Paulo, v. 3, n. 13, p. 1-165, out. 2004.

SEVERINO, Antônio Joaquim. Premissas e desafios da pesquisa na Pós-Graduação em Educação: da relevância social ao cuidado epistemológico. In: ENCONTRO DE PESQUISA DISCENTE DO PROGRAMA DE PÓS-GRADUAÇÃ̃ EM EDUCAÇÃO, 4., 2006, são Paulo. Anais... São Paulo: UNINOVE, 2006.

SEVERINO, Antônio Joaquim. Expansão do Ensino Superior: contextos, desafios, possibilidades. Avaliação, Campinas; Sorocaba, SP, v. 14, n. 2, p. 253-266, jul. 2009.

SEVERINO, Antônio Joaquim. Dimensão ética da investigação científica. Revista Práxis Educativa, Ponta Grossa, v. 9, n. 1, p. 199-208, jan./jun. 2014.

OLIVEIRA, Elizangela Lizardo. A formação científica do jovem universitário: um estudo com base no programa Institucional de bolsas de Iniciação Científica (PIBIC). 114 f. 2010. Dissertação (Mestrado) - Pontifícia Universidade Católica de São Paulo, São Paulo, 2010.

ROSA, Geraldo Antônio da; TREVISAN, Amarildo Luiz. Filosofia da tecnologia e educação: conservação ou crítica inovadora da modernidade? Avaliação, Campinas; Sorocaba, SP, v. 21, n. 3, p. 719-737, nov. 2016. 